\title{
Depression and anxiety in people affected by leprosy and lymphatic filariasis: a cross-sectional study in four States in India
}

\author{
Jennifer Mangeard-Lourme ${ }^{a}$, Guillermo Robert de Arquer ${ }^{a}$, \\ Jayaram Parasa ${ }^{\mathrm{b}}$, Rajni Kant Singh ${ }^{\mathrm{b}}$, Naveen Satle $^{\mathrm{b}}$ \& \\ Radhika Mamhidi ${ }^{b}$ \\ a'Lepra, 28 Middleborough, CO1 1TG, Colchester, UK \\ ${ }^{\mathrm{b}}$ LEPRA Society, Plot No 17, Krishnapuri Colony, West Marredpally, \\ Secunderabad, Telangana, India
}

Submitted 31 July 2020; Accepted 1 September 2020

\begin{abstract}
Summary
Objectives: Individual studies reported high levels of depression and anxiety among people affected with leprosy and lymphatic filariasis (LF), but they are often too small for a reliable comparison of prevalence mental ill health or its risk. The current study explores prevalence and risk factors of depression and anxiety within a large programme of a non-governmental organisation in India.

Methods: In a cross-sectional survey, we administered face-to-face Washington Group extended questions for Mental Health among leprosy and LF beneficiaries entering Lepra's programmes in Bihar, Andhra Pradesh, Odisha and Madhya Pradesh $(N=3706)$. Data were also gathered on risk factors widely reported in the literature, such as gender, age, caste, income, occupation, exclusion, disability and marital status. Results: Around 50\% of people affected with leprosy or LF reported experiences of depression and anxiety. Disability was found to be the main contributing factor for depression and anxiety, with exclusion, income, gender and age having a lower effect. Conclusion: The study confirms that mental ill health is a significant burden associated with leprosy and LF and that the mental health care needs of this population should be streamlined into the existing health and social services, and tailored according to disability status, age, marital status gender, income levels and taking into account experiences of discrimination. Current momentum for joint efforts to address skin NTDs presents a window of opportunity.
\end{abstract}

Keywords: Leprosy, lymphatic filariasis, depression, anxiety, community stigma

\section{Introduction}

Neglected tropical diseases (NTDs) are a diverse group of twenty communicable diseases that prevail in tropical conditions affecting one billion people in 149 low and middle income

Correspondence to: Jennifer Mangeard-Lourme (e-mail: jenniml@espritssolidaires.com) 
countries. ${ }^{1}$ If not diagnosed and treated early, they can lead to disability and as such are a significant contributor to health life years $\operatorname{los}^{2}$ with a significant, negative economic impact on the people affected and their local communities. ${ }^{2,3}$

In addition to physical and socio-economic hardship experienced by people affected by NTDs, it is now widely accepted that mental ill health and psychosocial disabilities are also common $^{4}$ and estimates point to one in two people affected by NTDs experiencing depression and/or anxiety across different contexts. ${ }^{5,6}$. Stigma or experiences of discrimination have been the most significant risk factor for depression and anxiety. ${ }^{7-12}$ This is particularly the case for the ten NTDs which have manifestation on the skin in the form of lumps or swelling, ulcers, swollen limbs and patches on the faces and body ${ }^{13}$ and where opportunities for concerted efforts on programmatic side are met with challenges of stigmatisation of the people affected NTDs. ${ }^{14-16}$

Many skin NTDs have been found to be associated with higher levels of mental distress than the general population, including leprosy ${ }^{12,17-21}$ and lymphatic filariasis (LF). ${ }^{22-29}$ The prevalence of depression among people affected with leprosy across contexts is around $50 \%$ and ranges from $10 \%$ to $76 \% .^{12,30-32}$. High suicide rates were reported in individual studies in Japan, ${ }^{33}$ India ${ }^{34}$ and in Brazil. ${ }^{35}$ Anxiety affected an estimated $20 \%$ of people affected with leprosy. ${ }^{7,36}$.

In the case of LF, $70 \%$ of affected people in Togo reported high risk of depression, ${ }^{37} 47.8 \%$ in China $^{38}$ and practically everyone in one study in India with $97 \%$ at high risk of depression. ${ }^{39}$

Apart from stigma and discrimination, reported risks for depression and anxiety included clinical, demographic and economic factors for both leprosy and LF.

For leprosy, the side effects of standard multi-drug treatment (MDT) have been linked to higher levels of anxiety in patients, as have painful reactions, ulcers and disability across contexts including India, ${ }^{7,17}$ Bangladesh, ${ }^{8}$ Ethiopia, ${ }^{9}$ Nigeria $^{40}$ and Thailand. ${ }^{31}$ The multibacillary type of leprosy (MB), which is characterised by a higher number of lesions (as opposed to the paucibacillary (PB) type), was also associated with higher psychiatric disturbance in hospitalised patients in India. ${ }^{11}$

In LF, pain was noted as a major risk factor for mental distress in patients with chronic manifestations, in particular acute attacks. ${ }^{27,38,41}$ Disability has been linked to depression, ${ }^{24,28,42}$ especially the when associated with reduced mobility. ${ }^{38}$

For men affected by hydrocele, a form of LF characterised by swelling of the scrotum, the major risks for anxiety and depression were dissatisfaction of their spouse/partners if they were in a relationship, or worries about finding a wife for single men. ${ }^{26,43,44}$

Relationship status also played a part for people affected by leprosy. Some studies found that being married was a source of mental distress, ${ }^{8,31,45}$ whereas other research identified not being married as a factor for depression or anxiety. ${ }^{9,40}$ The role the patient held in the family appeared to explain variations in the impact of marital life on a patient's mental health. ${ }^{31}$

The length of the experience of LF and mental distress tended to be positively correlated, ${ }^{40}$ while older people affected by leprosy reported higher levels of distress. $8,31,33,46,47$

Gender played a role for both leprosy and LF patients, with women experiencing higher levels of depression or anxiety than men. ${ }^{31,40,47}$

Unemployment and a lack of income was a risk factor for the development of depression and anxiety in both groups $7,8,25,40,45,47$ as well as low education levels or knowledge $8,9,11,40,45,47$ and restrictions upon people's ability to exercise their civil and political rights. ${ }^{5}$

Although existing studies offer valuable information on the prevalence of and risks associated with depression and anxiety among people affected by leprosy and LF, their sample sizes 
tend to be small, varying between 30 and 494 participants, with a mean of 161. Some studies ran weak statistical tests on their data sets with some not achieving statistical significance, ${ }^{21,35}$ some did not adjust for confounding variables $7,17,31,33,35,45,46,48$ and others did not measure effects. ${ }^{9,17,21,35,48}$ This makes it difficult to establish major risks and, given the nature of observational studies, formally test causal pathways. Also a higher level of certainty is required to arrive at more reliable estimates of the prevalence of depression and anxiety and, with that, plan how best to address the mental health needs and mental health care integration into NTD treatment packages. ${ }^{4}$

\section{AIM}

The aim of the current study is to assess the scale for depression and anxiety among people affected by leprosy and LF seeking medical care in India, and the main risks associated with poor mental health.

The specific objectives were two-fold: firstly, to estimate the prevalence of depression and anxiety among people affected by leprosy and LF, at their point of contact with Referral Centres run by LEPRA Society, a non-governmental organisation, across four states between April 2017 and October 2018; and, at the same time, to estimate the effect of those risks that are most commonly reported in the literature, as discussed above.

\section{Methods}

The study was conducted in seven Districts across four states in India, including Panna (Madhya Pradesh), Samastipur (Bihar), Koraput and Nabarangpur (Odisha), and Krishna and Vizianagaram (Andhra Pradesh) between April 2017 and October 2018.

The study surveyed people affected by leprosy and LF at the point of enrolment into a new project (Samastipur) or at the time services at Lepra Society's Referral Centres were accessed (the remaining six Districts). There were no mental health interventions offered by Lepra Society at the time.

The outcome of interest - anxiety and depression - was based on four out of the six questions of the subset 'ANXIETY AND DEPRESSION' of the Washington Group Mental Health (WGMH) Extended Question Set on Functioning ${ }^{49}$ (see Table 1). Questions 2 and 4 related to '[Do/Does] [you/he/she] take medication for these feelings?' were excluded given they did not fit the local context where medication for depression and anxiety are extremely hard to access. As indicated in Table 2, the outcomes were dichotomised post-data collection to facilitate statistical analysis with the lowest value/least mental health problem being the reference group and reports of higher levels of mental distress grouped together.

The four relevant questions were embedded into a questionnaire that also collected socioeconomic indicators. In this context, seven risk factors were included, as identified in the literature, and included gender, age, caste, income, exclusion, disability and marital status. Occupation was also often reported in the literature but it overlapped with income and the latter was deemed more relevant and practical.

Exclusion was defined as reports of exclusion within the family, at work or within the community (not attending social and community activities) from the patients directly. Income was defined as personal monthly income and this was transformed into a binary variable with (i) zero income and (ii) income above zero (the median monthly income reported by target participants was found to be approximately zero).

People newly diagnosed with leprosy or LF/hydrocele were eligible for the study. In Bihar and Odisha, participants were recruited within Lepra Society's Referral Centres at the point 
Table 1. Selected Washington Group Mental Health questions and constructed binary outcomes

\begin{tabular}{|c|c|c|c|}
\hline id & WGMH questions & WGMH available answers & Binary outcome \\
\hline 1 & $\begin{array}{l}\text { How often do you feel worried, } \\
\text { nervous or anxious? }\end{array}$ & $\begin{array}{l}\text { - Daily } \\
\text { - Weekly } \\
\text { - Monthly } \\
\text { - Afew times a year } \\
\text { - Never } \\
\text { - Don't Know }\end{array}$ & $\begin{array}{l}\text { Frequent Anxiety }(\boldsymbol{F A}) \\
\cdot \text { Never } \\
\cdot \text { At least once a year }\end{array}$ \\
\hline 2 & $\begin{array}{l}\text { Thinking about the last time you felt } \\
\text { worried, nervous or anxious, how } \\
\text { would you describe the level of these } \\
\text { feelings }\end{array}$ & $\begin{array}{l}\text { - A little } \\
\text { - A lot } \\
\text { - Somewhere in between a } \\
\text { little and a lot }\end{array}$ & $\begin{array}{l}\text { Intense Anxiety (IA) } \\
\cdot \text { A little } \\
\cdot \text { Moderate to severe }\end{array}$ \\
\hline 3 & How often do you feel depressed? & $\begin{array}{l}\text { - Daily } \\
\text { - Weekly } \\
\text { - Monthly } \\
\text { - A few times a year } \\
\text { - Never } \\
\text { - Don't Know }\end{array}$ & $\begin{array}{l}\text { Frequent Depression } \\
(\boldsymbol{F D}) \\
\text { - Never } \\
\text { - At least once a year }\end{array}$ \\
\hline 4 & $\begin{array}{l}\text { Thinking about the last time you felt } \\
\text { depressed, how depressed did you } \\
\text { feel? }\end{array}$ & $\begin{array}{l}\text { - A little } \\
\text { - A lot } \\
\text { - Somewhere in between a } \\
\text { little and a lot }\end{array}$ & $\begin{array}{l}\text { Intense Depression }(I D) \\
\cdot \text { A little } \\
\cdot \text { Moderate to severe }\end{array}$ \\
\hline
\end{tabular}

$F A$ : Frequent Anxiety FD: Frequent Depression IA: Intense Anxiety ID: Intense Depression.

of contact with the new patients. In such cases, the diagnosis was confirmed either by Lepra Society or at the government health facilities and patients reached the Referral Centre through a referral for further care. In Panna, participants were recruited as part of a baseline data collection for a larger study where 'newly diagnosed patients' were operationalised as those diagnosed up to three months prior to the interview. This was self-reported and the data were collected through face-to-face interviews by Accredited Social Health Activists (ASHAs) and volunteers after a dedicated one-day training. Consent Forms were administered in hard copies and replies to the questionnaire recorded on paper. The data were verified and validated by trained project Block Health Coordinators and consolidated using KoBo Collect, a free opensource application that runs on smartphones and allows multiple survey forms to be completed digitally.

\section{STATISTICAL ANALYSIS}

Wald Chi-square tests were used through univariate logistic regressions to measure the association between potential risk factors and constructed WGMH binary outcomes. Associations were only considered significant at $p<0.05$ and step-wise logistic regressions run with adjustments for gender, age, monthly income, exclusion, disability and marital status. Risk Ratios (RR) were calculated by converting the Odd Ratio (OR) using the following calculation, where $\mathrm{RR}=$ Risk Ratio, $\mathrm{OR}=$ Odds Ratio and $p_{c}=$ Prevalence in the non-exposed group:

$$
R R=\frac{O R}{\left(1-p_{c}\right)+\left(p_{c} * O R\right)} .
$$


Table 2. Distribution of possible MH risk factors by gender among surveyed leprosy patients

\begin{tabular}{|c|c|c|c|c|c|c|}
\hline \multirow[t]{2}{*}{ Characteristic } & \multicolumn{3}{|c|}{ Leprosy (\%) } & \multicolumn{3}{|c|}{ Lymphatic filariasis (\%) } \\
\hline & Males & Females & Total & Males & Females & Total \\
\hline \multicolumn{7}{|l|}{ Age } \\
\hline $19-40$ & $430(45)$ & $204(45)$ & $634(45)$ & $760(43)$ & $120(23)$ & $880(38)$ \\
\hline $41-60$ & $376(40)$ & $189(42)$ & $565(40)$ & $751(42)$ & $259(50)$ & $1010(44)$ \\
\hline$>60$ & $145(15)$ & $60(13)$ & $205(15)$ & $277(15)$ & $135(26)$ & $412(18)$ \\
\hline \multicolumn{7}{|l|}{ Marital status } \\
\hline Married & $845(89)$ & $377(83)$ & $1222(87)$ & $1515(85)$ & $391(76)$ & $1906(83)$ \\
\hline Divorced/sep. & $8(1)$ & $6(1)$ & & $4(0)$ & $5(1)$ & $9(0)$ \\
\hline Widowed & $20(2)$ & $45(10)$ & $14(1)$ & $47(3)$ & $113(22)$ & $160(7)$ \\
\hline Single & $78(8)$ & $25(6)$ & $\begin{array}{c}65(5) \\
103(7)\end{array}$ & $222(12)$ & $5(1)$ & $227(10)$ \\
\hline \multicolumn{7}{|l|}{ Caste } \\
\hline General & $132(14)$ & $39(9)$ & $171(12)$ & $395(22)$ & $170(33)$ & $565(25)$ \\
\hline OBC & $412(43)$ & $209(46)$ & $621(44)$ & $934(52)$ & $253(49)$ & $1187(52)$ \\
\hline $\mathrm{SC}$ & $227(24)$ & $110(24)$ & 337 (24) & 339 (19) & $70(14)$ & 409 (18) \\
\hline ST & $174(18)$ & $94(21)$ & 268 (19) & $112(6)$ & $17(3)$ & $129(6)$ \\
\hline Other & $5(1)$ & $0(0)$ & $5(0)$ & $7(0)$ & $4(1)$ & $11(0)$ \\
\hline \multicolumn{7}{|l|}{ Occupation } \\
\hline Agric. worker & $480(51)$ & $55(12)$ & $535(38)$ & $856(48)$ & $103(20)$ & $959(42)$ \\
\hline DWL & $328(35)$ & $81(18)$ & 409 (29) & $627(35)$ & $81(16)$ & $708(31)$ \\
\hline Factory worker & $28(3)$ & $4(1)$ & $32(2)$ & $53(3)$ & $2(0)$ & $55(3)$ \\
\hline Housewife & $0(0)$ & $258(57)$ & $258(18)$ & $0(0)$ & $263(51)$ & $263(11)$ \\
\hline Private & $11(1)$ & $5(1)$ & $16(1)$ & $43(2)$ & $22(4)$ & $65(3)$ \\
\hline SME owner & $58(6)$ & $25(6)$ & $83(6)$ & $165(9)$ & $29(6)$ & $194(8)$ \\
\hline Student & $22(2)$ & $16(4)$ & $38(3)$ & $27(2)$ & $9(2)$ & $36(2)$ \\
\hline Other & $23(2)$ & $8(2)$ & $31(2)$ & $15(1)$ & $4(1)$ & $19(1)$ \\
\hline \multicolumn{7}{|l|}{ Monthly Income } \\
\hline $\mathrm{MI}=0$ & $297(31)$ & $204(45)$ & $501(36)$ & $579(32)$ & $258(50)$ & 837 (36) \\
\hline $\mathrm{MI}>0$ & $654(69)$ & $249(55)$ & 903 (64) & $1209(68)$ & $256(50)$ & $1465(64)$ \\
\hline \multicolumn{7}{|l|}{ Disability grade } \\
\hline Gr-0/Stage-1 & $298(31)$ & $168(37)$ & $466(33)$ & $1619(91)$ & $229(45)$ & $1848(80)$ \\
\hline Gr-I/Stage-2 & 464 (49) & $203(45)$ & $667(48)$ & $123(7)$ & $195(38)$ & $318(14)$ \\
\hline Gr-2/Stage-3 & $189(20)$ & $82(18)$ & $271(19)$ & $46(3)$ & $90(18)$ & $136(6)$ \\
\hline \multicolumn{7}{|l|}{ Exclusion } \\
\hline No & 349 (37) & $175(39)$ & $524(37)$ & $850(48)$ & $284(55)$ & $1134(49)$ \\
\hline Yes & $602(63)$ & $278(61)$ & $880(63)$ & $938(52)$ & $230(45)$ & $1168(51)$ \\
\hline \multirow[t]{2}{*}{ Total } & $951(100)$ & $453(100)$ & $1404(100)$ & $1788(100)$ & $514(100)$ & $2302(100)$ \\
\hline & & & Outcome & & & \\
\hline \multirow[t]{2}{*}{ Category } & Anxiety & $(\%)$ & & Depression & $(\%)$ & \\
\hline & Leprosy & $\mathrm{LF}$ & & Leprosy & $\mathrm{LF}$ & \\
\hline \multicolumn{7}{|l|}{ Frequency } \\
\hline Never & $146(10)$ & $214(9)$ & & $128(9)$ & $184(8)$ & \\
\hline Few times a year & $114(8)$ & $231(10)$ & & $122(9)$ & $223(10)$ & \\
\hline Monthly & $76(5)$ & $150(7)$ & & $137(10)$ & $168(7)$ & \\
\hline Weekly & $350(25)$ & $421(18)$ & & $327(23)$ & $499(22)$ & \\
\hline Daily & $560(40)$ & $1086(47)$ & & $507(36)$ & $962(42)$ & \\
\hline Don't Know & $158(11)$ & $200(9)$ & & $183(13)$ & $266(12)$ & \\
\hline
\end{tabular}


Table 2. (Continued)

\begin{tabular}{|c|c|c|c|c|c|c|}
\hline \multirow[t]{2}{*}{ Characteristic } & \multicolumn{3}{|c|}{ Leprosy (\%) } & \multicolumn{3}{|c|}{ Lymphatic filariasis (\%) } \\
\hline & Males & Females & Total & Males & Females & Total \\
\hline \multicolumn{7}{|l|}{ Intensity } \\
\hline Little & $555(40)$ & $1276(55)$ & & $516(37)$ & $1109(48)$ & \\
\hline BL\&L & $236(17)$ & $251(11)$ & & $266(19)$ & $257(11)$ & \\
\hline Lot & $313(22)$ & $348(15)$ & & $315(22)$ & $475(21)$ & \\
\hline Don't Know & $300(21)$ & 427 (19) & & $307(22)$ & $461(20)$ & \\
\hline Total & $1404(100)$ & $2302(100)$ & & $1404(100)$ & $2302(100)$ & \\
\hline
\end{tabular}

SC: Scheduled Castes, ST: Scheduled Tribes, MH: Mental Health, DWL: Daily Wage Worker, SME: Small/Medium Enterprise, MI: Monthly Income; BL\&L: Between a Little and a Lot, LF: Lymphatic Filariasis, WGMH: Washington Group Mental Health.

\section{Results}

A total of 2114 new leprosy cases and 2559 new LF cases were registered by LEPRA Society and recruited for the study in targeted districts over the study period. The vast majority of LF and leprosy participants were from Panna District (Madhya Pradesh), 90\% and 62\%, respectively. After cleaning the data to exclude participants from Panna who were diagnosed more than three months prior to being interviewed and new patients with missing data, a total of 1404 new leprosy cases and 2302 new LF cases formed the final sample (see Table 2). In both cases, men were over-represented $68 \%$ males vs $32 \%$ females in leprosy and $78 \%$ males vs $22 \%$ females in LF. A total of $43 \%$ of leprosy and $24 \%$ of LF cases belonged to Schedule Castes or Scheduled Tribes, a group of marginalised communities in India. Over one in five participants were married and over two in three participants reported having no income at all. Women were mostly housewives (57\% leprosy, $51 \%$ LF) and men agricultural workers $(51 \%$ leprosy, $48 \% \mathrm{LF})$.

The prevalence of disability was high among participants affected by leprosy, with over two in three people reporting Grade-1 or Grade-2 Disability, compared to one in five people affected with LF with Disability Stage 2 or 3. More than half of the participants reported experience of exclusion, whether it was within the family unit, at work, or in their community by being excluded from social events (63\% leprosy, $51 \% \mathrm{LF}$ ).

More than 9 in 10 participants reported having at least one episode of either anxiety or depression in a year with around 4 in 10 participants reporting daily experience of anxiety or depression (Table 3). The frequency of experienced anxiety and depression were broadly comparable between leprosy and LF.

Participants affected by leprosy, however, reported higher intensity of anxiety than participants affected by LF with $39 \%$ and $26 \%$, respectively, reporting more than a little anxiety to a lot of anxiety. Similarly, $41 \%$ of the people affected by leprosy compared to $32 \%$ of the people affected by LF experienced more than a little to a lot of depression.

Wald and Chi-square tests from univariate logistic regression showed evidence for crude association between disability, exclusion, income, caste and age, with frequent anxiety and depression among people affected by leprosy (see Tables 4 and 5). However, we only found crude association between exclusion, income and marital status, with the outcomes of frequency, among LF patients. It is worth noting that age had a different effect on people affected by leprosy and LF, with young people affected by leprosy having a higher risk of poor mental health (19 to 40 years old), whereas for LF, it was the elderly (41 to 60 years old). 
Table 3. Summary of adjusted measures of effect between risk factors and WGMH binary outcomes among people affected by leprosy and LF

\begin{tabular}{|c|c|c|c|}
\hline Outcome & Risk factor $(\mathrm{pv}<0.05)$ & Adjusted OR (95\% CI) & $\mathbf{R R}$ \\
\hline \multicolumn{4}{|c|}{ Leprosy } \\
\hline \multirow[t]{5}{*}{ Frequent Anxiety } & Aged $19-40$ & $1.85(1.25-2.78)$ & 1.04 \\
\hline & No income & $2.23(1.46-3.43)$ & 1.08 \\
\hline & Disability grade-1 & $5.05(3.09-8.25)$ & 1.24 \\
\hline & Disability grade-2 & $3.18(1.89-5.35)$ & 1.20 \\
\hline & Exclusion & $13.14(7.71-22.40)$ & 1.32 \\
\hline \multirow[t]{5}{*}{ Frequent Depression } & Aged $19-40$ & $1.81(1.19-2.77)$ & 1.04 \\
\hline & No income & $2.74(1.72-4.40)$ & 1.09 \\
\hline & Disability grade-1 & $4.52(2.71-7.51)$ & 1.20 \\
\hline & Disability grade-2 & $3.13(1.80-5.45)$ & 1.17 \\
\hline & Exclusion & $13.86(7.88-24.37)$ & 1.29 \\
\hline \multirow[t]{3}{*}{ Intense Anxiety } & Widowed & $2.40(1.22-4.73)$ & 1.42 \\
\hline & Disability grade-2 & $3.60(2.47-5.26)$ & 1.70 \\
\hline & Exclusion & $2.00(1.52-2.64)$ & 1.41 \\
\hline \multirow[t]{4}{*}{ Intense Depression } & Widowed & $2.15(1.07-4.36)$ & 1.34 \\
\hline & Disability grade-2 & $4.57(3.02-6.91)$ & 1.78 \\
\hline & Exclusion & $1.86(1.40-2.46)$ & 1.32 \\
\hline & Lymphatic Filari & & \\
\hline \multirow[t]{2}{*}{ Frequent Anxiety } & No income & $1.55(1.13-2.13)$ & 1.04 \\
\hline & Exclusion & $2.31(1.71-3.11)$ & 1.09 \\
\hline \multirow[t]{2}{*}{ Frequent Depression } & Single & $2.49(1.20-5.17)$ & 1.06 \\
\hline & Exclusion & $2.72(1.96-3.77)$ & 1.09 \\
\hline \multirow[t]{5}{*}{ Intense Anxiety } & Female gender & $1.36(1.03-1.81)$ & 1.24 \\
\hline & No income & $1.27(1.03-1.58)$ & 1.18 \\
\hline & Disability grade-1 & $1.97(1.46-2.69)$ & 1.57 \\
\hline & Disability grade-2 & $11.69(6.84-20.00)$ & 3.09 \\
\hline & Exclusion & $0.60(0.49-0.75)$ & 0.71 \\
\hline \multirow[t]{5}{*}{ Intense Depression } & Aged $41-60$ & $1.29(1.02-1.62)$ & 1.17 \\
\hline & Widowed & $1.57(1.04-2.36)$ & 1.29 \\
\hline & No income & $1.41(1.15-1.73)$ & 1.23 \\
\hline & Disability grade-1 & $1.69(1.25-2.29)$ & 1.36 \\
\hline & Disability grade-2 & $7.76(4.47-13.48)$ & 2.31 \\
\hline
\end{tabular}

OR: Odds Ratio RR: Risk Ratio.

Multiple logistic regression showed that people with disability affected by leprosy had 20$30 \%$ higher risk ratios for both frequency and intensity of depression and anxiety. Exclusion also played a significant role among people affected by leprosy, with risk ratios for mental health indicators being $30 \%$ higher for participants who experienced exclusion.

In LF, people experiencing exclusion or with zero-income had very modest increase in risk ratio for frequent anxiety, under $10 \%$. Similarly, exclusion and being single were found to also be weak risk factors for frequent depression, also under $10 \%$ effect.

Exclusion, G2D and widowed individuals were found to be possible cross-cutting risk factors for intensity of depression and anxiety. However, people aged over 60 and zero-income are also possible risk factors for intense depression.

The diagram below (Figure 1) summarises the risk factors that had an effect on depression and anxiety. They appear in black boxes. Note that the risk factor 'exclusion' has a weak effect in the case of LF. 


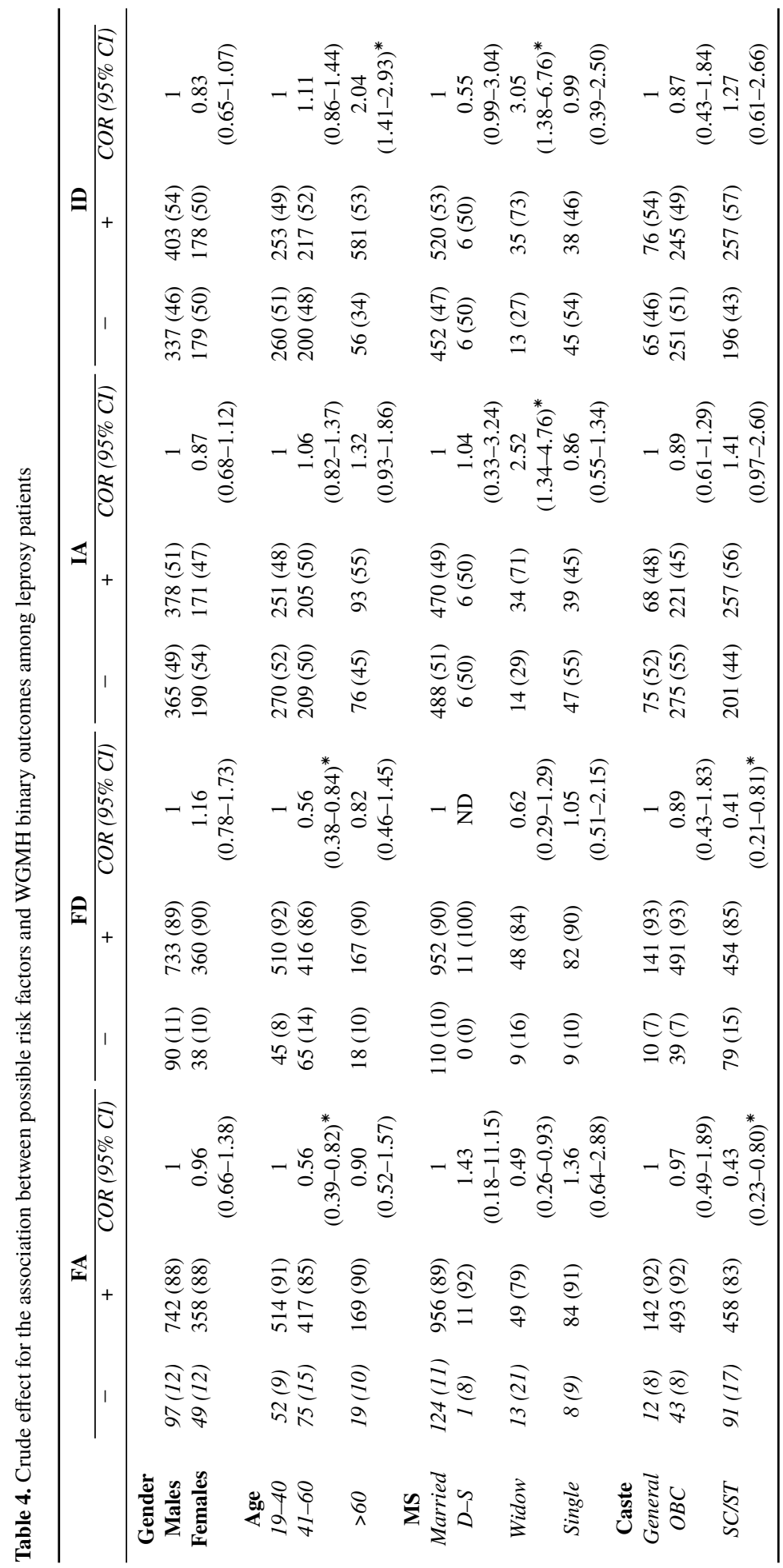









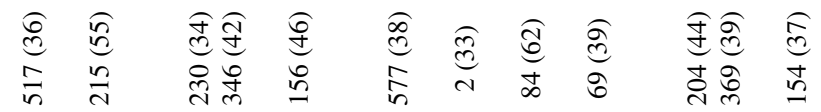

卉守

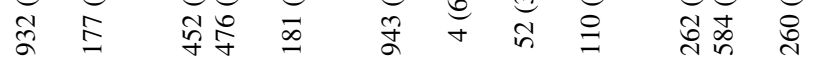

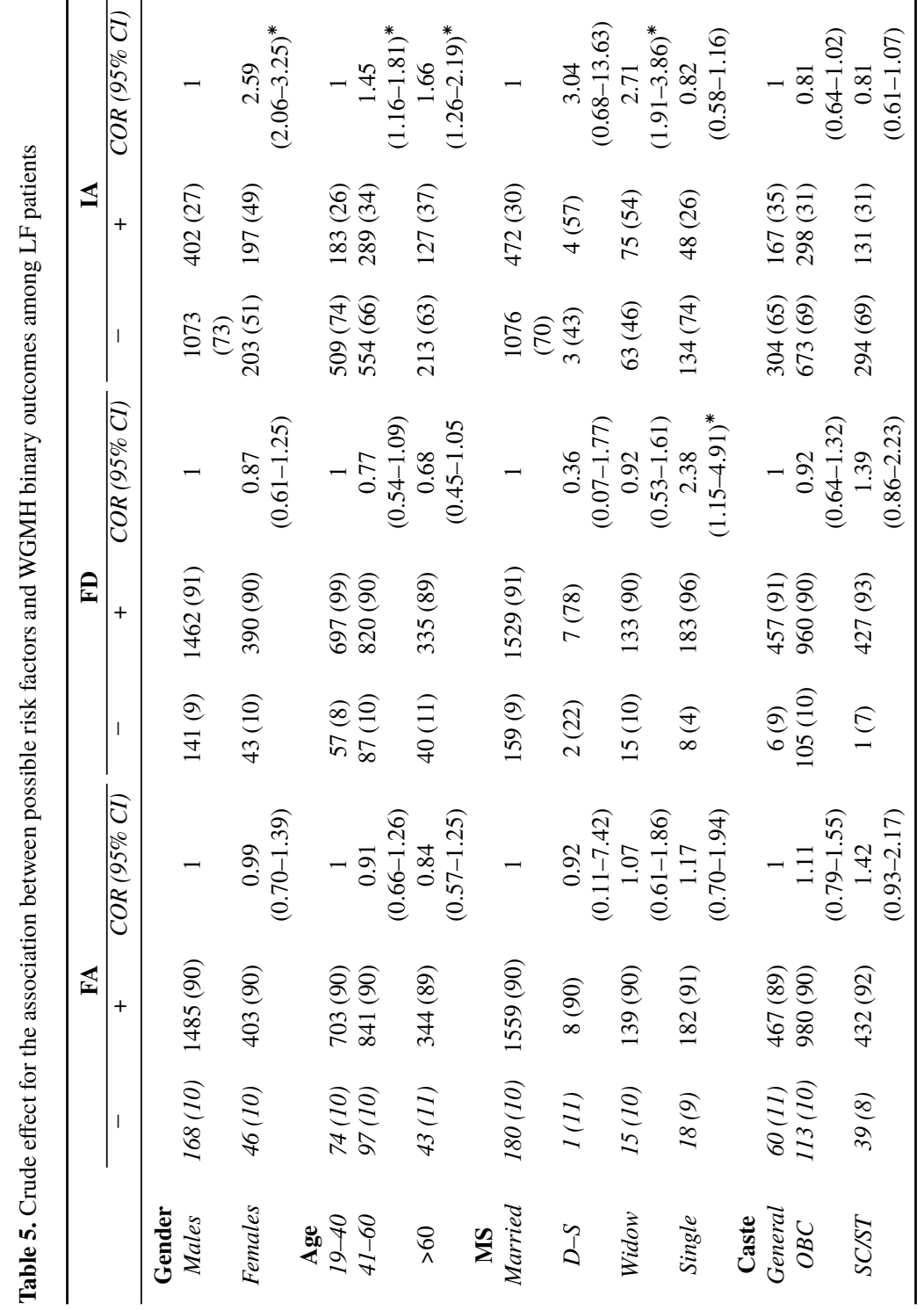




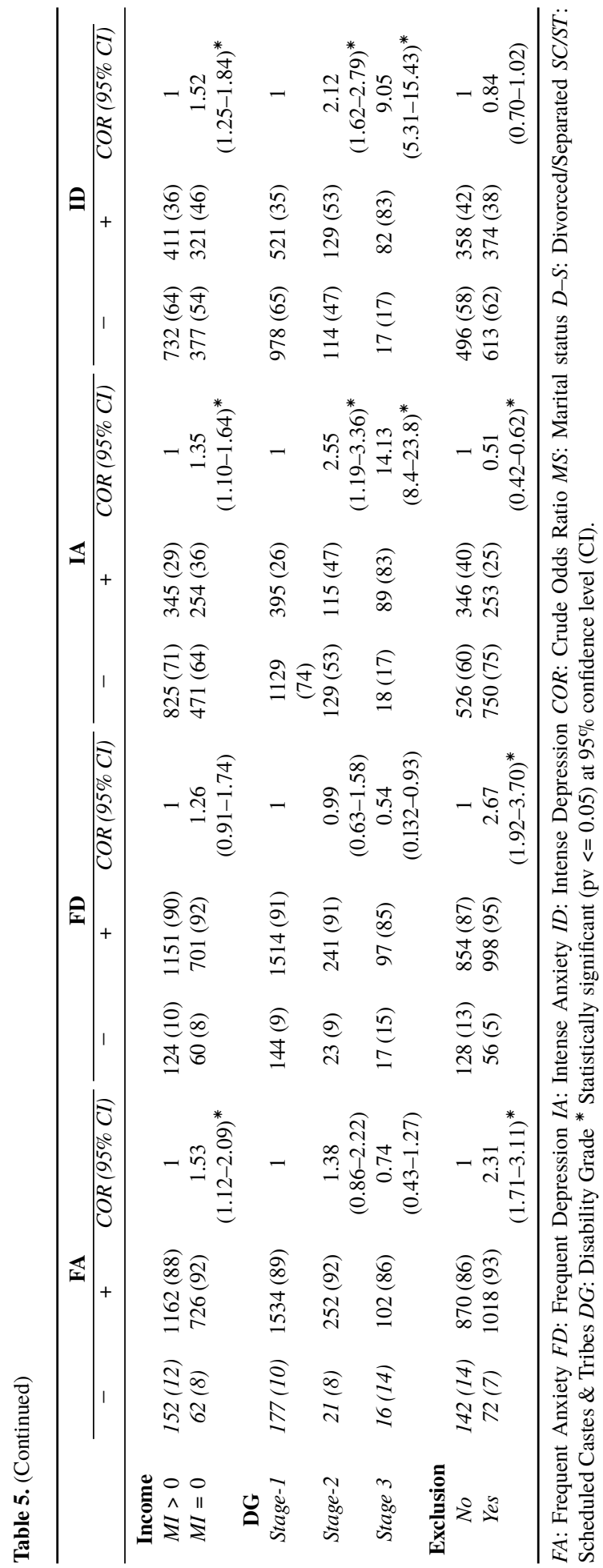




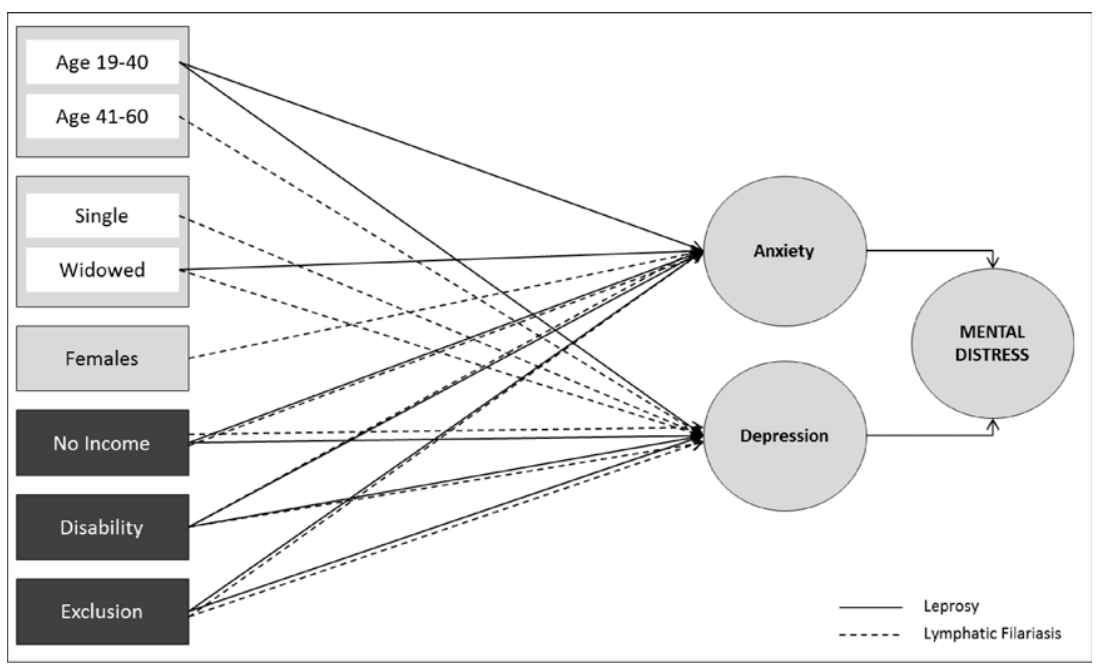

Figure 1 Effect of risk factors on the depression and anxiety status of leprosy and LF patients.

\section{STRENGTHS AND WEAKNESSES}

The strength of the study is that it involved a larger sample of nearly 4000 people, using a common questionnaire and more robust statistical approaches than previous studies and that the exploration of risk factors was based on a literature review. ${ }^{6}$

There are a few limitations that need consideration when interpreting the findings of this paper. First, this study explored associations whose causality cannot be inferred due to an observational, cross-sectional study design. Secondly, mental health outcomes have only considered WGMH questions in terms of depression and anxiety and alternative mental health scoring systems may have given different results. Thirdly, the risk factor exclusion has been constructed using self-reports only in three areas of the patients' lives. This may potentially result in underestimating the more global effect exclusion has on an individual. There may be further relevant risk factors for depression and anxiety not captured in this study. Contextual differences within different administrative areas pertaining to health, social, or mental health systems were not accounted for. In fact, the study is most representative of Panna, especially for LF, with over $90 \%$ of the sample recruited in that area. Finally, about $20 \%$ of all respondents replied to the questions in WGMH with 'Don't know' indicating low mental health literacy and/or skill or engagement of ASHAs.

\section{Discussion}

The risk factors found significant in the study are in line with the literature, with disability, exclusion and, for women, being a widow, having the highest association with depression and anxiety, and their intensity among people affected by leprosy and LF.

This finding supports our supposition that disability is a distinct risk factor for depression and anxiety and implies that mental health care should be provided along with the disability and pain management component of NTD treatment packages. It clearly directs us towards an intervention in which mental disabilities are treated at the same time as physical disabilities. "No health without mental health". 
There are implications for future research. Next steps are to determine when to provide mental health care, to whom and how. In our study gender was a confirmed risk factor for depression and anxiety, as was being a widow. This may be linked to income as most women did not have an income and had to rely on other family members for financial support. In India, this is known to have major implications on women's health seeking behaviours, on their prognosis and their autonomy ${ }^{50}$ and could contribute to women being more susceptible to mental health issues. Mental health interventions need to be able to reach different groups of women affected by leprosy and LF, assess causes of women's distress and be able to support them and refer to services, as needed. This will require a multi-sectoral intervention.

Feeling of exclusion was confirmed to be linked to poor mental health in this study. Future mental health interventions need to go beyond addressing the internalised experiences of prejudice and discrimination alone i.e. self-stigmatisation and victim-blaming, ${ }^{51}$ but tackle structural and normative factors that lead to discrimination.

In terms of timing, mental health should not be an afterthought to medical treatment, for example assessing and giving mental health support only after the completion of MDT or the management of complications such as reactions. ${ }^{52,53}$ This may be very late for the affected individuals and not optimum for their full recovery.

\section{Conclusion}

The study confirms that mental ill health is a significant burden for people affected by leprosy and LF and that mental health care should be given its proper place in NTD treatment packages. It also suggests that for both groups, mental distress is influenced by physical disabilities and directs us towards a skin NTD intervention where mental disabilities are treated jointly with physical disabilities, along the recognition, diagnosis, treatment, self-care and wound management pathway and tailored to different risk groups for anxiety and depression, according to gender, experiences of exclusion, marital and financial status. Multi-sectoral intervention, informed by the needs and voices of the people affected, is a long term aim. Given that these two NTDs are co-endemic in many parts of the world, and particularly in India, albeit not as prevalent as many non-transmittable diseases, such as cardiovascular diseases, allows for joint action and a stronger voice.

In fact, the momentum created by the new skin NTD approaches, ${ }^{54}$ with mobile applications aiding their recognition, ${ }^{55,56}$ multi-disciplinary large-scale research to identify the best ways to improve the diagnosis, treatment and quality of life for the people affected by skin $\mathrm{NTDs}^{57}$ and with a new WHO department devoted to skin NTDs already providing tools and resources, ${ }^{13,14,56}$ this is a window of opportunity for streamlining mental health across the care pathway. Benefits associated with the intervention outstrip the costs: evidence already exists that scaling up treatment for depression and anxiety worldwide is predicted to give a good return on investment. ${ }^{58}$

\section{Acknowledgements}

We want to thank Paul Watson, Lepra's Head of Programmes, and Milena Simic, Programmes Manager, for their advice and thorough proofreading.

\section{Financial Support}

The study was commissioned and run by Lepra, a UK-based international development charity, in partnership with LEPRA Society, its Indian counterpart. 
This research received no specific grant from any funding agency, commercial or not-forprofit sectors.

\section{Conflict of Interest}

The authors report no conflicts of interest.

\section{Ethical Standards}

The research did not involve human and/or animal experimentation.

The authors assert that all procedures contributing to this work comply with the ethical standards of the relevant national and institutional guides.

\section{Author contributions}

These authors contributed equally: Jennifer Mangeard-Lourme and Guillermo Robert de Arquer. These other authors contributed equally: Jayaram Parasa, Rajni Kant Singh, Naveen Satle \& Radhika Mamhidi.

\section{References}

1 World Health Organisation. Neglected tropical diseases. 2019.

2 Hotez PAM, Marı-Gloria Basain BI, Bourne R, Boussinesq M, Brooker S, Brown AS, Buckle G, Budke C, Carabin H, Coffeng L, Furst T, Halasa Y, Jasrasaria R, Johns N, Keiser J, King C, Lozano R, Murdoch M, O’Hanlon S, Pion DS, Pullan R, Ramaiah K, Roberts T, Shepard D, Smith J, Stolk W, Undurraga E, Utzinger J, Wang M, Murray C, Naghavi M, The Global Burden of Disease Study 2010: Interpretation and implications for the neglected tropical diseases. PLoS Negl Trop Dis, 2014; 8(7): https://journals.plos.org/plosntds/article/fil e?id=10.1371/journal.pntd.0002865\&type=printable

3 Herricks JHP, Wanga V, Coffeng 1, Haagsma J, Basáñez MG, Buckle G, Budke C, Carabin H, Fèvre E, Fürst T, Halasa Y, King C, Murdoch M, Ramaiah K, Shepard D, Stolk W, Undurraga E, Stanaway E, Naghavi M, Murray C. The global burden of disease study 2013: What does it mean for the NTDs? 2018.

4 Bailey Freddie EJ, Jidda M, Brakel WH van, Addiss David G., Molyneux David H, Neglected tropical diseases and mental health: progress, partnerships, and integration. Trends Parasitol, 2019; 35(1):195-201.

5 Litt E, Baker MC, Molyneux D. Neglected tropical diseases and mental health: a perspective on comorbidity. Trends Parasitol, 2012; 28(5): 195-201.

6 Mangeard-Lourme J. Building the case for the integration of mental health services in leprosy and lymphatic filariasis programmes. InfoNTD, 2018.

7 Thwaites VAV, Rao K. Sources of anxiety amongst leprosy patients in urban treatment setting in Hyderabad, India. Lepr Rev, 2014; 85(4): 328-331.

8 Tsutsumi AIT, Akulislam MD, Amed JU, Nakahara S, Takagi F, Wakai S. Depressive status of leprosy patients in Bangladesh: association with self-perception of stigma. Lepr Rev, 2004; 75: 57-66.

9 Damte AB, Haftu Berhe HG/H. Prevalence and associated factors of mental distress among leprosy patients at alert hospital out patient clinic Addis Ababa, Ethiopia. Int J Pharm Sci Res, 2011; 4(3): 1176-1182.

10 Tsutsumi AIT, Islam MK, Wakai S. The quality of life, mental health and perceived stigma of leprosy patients in Bangladesh. Soc Sci Med, 2007, 64(12):2443-2453

11 Bharath S, Raghuram S. Correlates of psychiatric morbidity in patients with leprosy. Indian J Lepr, 2001; 73(3): 236-243.

12 Singh GP. Psychosocial aspects of Hansen's disease (leprosy). Indian Dermatol Online J, 2012, 32012: 166-170.

13 World Health Organisation. Skin NTDs 2020 [Available from: https://www.who.int/neglected_diseases/skin-n tds/en/\#: :text=Skin \%20NTDs\%20are\%20a\%20group,disability \%2C\%20stigmatization \%20and\%20socioeco nomic $\% 20$ problems.

14 WHO/Department of control of neglected tropical diseases. Recognizing neglected tropical diseases through changes on the skin: A training guide for front-line health workers. 2018.

15 WHO/Department of control of neglected tropical diseases. Wound and Lymphoedema Management. 2010.

16 Yotsu RR. Integrated management of skin NTDs-lessons learned from existing practice and field research. Trop Med Infect Dis, 2018; 3(4): 120. 
17 Kumar JH, Verghese A. Psychiatric disturbances among leprosy patients. An epidemiological study. Int J Lepr Other Mycobact Dis, 1980; 48(4): 431-434.

18 Mhasawade BC. Leprosy-a case for mental health care. Lepr India, 1983; 55(2): 310-313.

19 Jindal KC, Singh GP, Mohan V, Mahajan BB. Psychiatric morbidity among inmates of leprosy homes. Indian J Psychol Med, 2013, 352013: 335-340.

20 Leekassa R, Bizuneh E, Alem A. Prevalence of mental distress in the outpatient clinic of a specialized leprosy hospital. Addis Ababa, Ethiopia, 2002. Lepr Rev, 2005; 75(4): 367-375.

21 Weiss MG, Doongaji DR, Siddhartha S, Wypij D, Pathare S, Bhatawdekar M et al. The Explanatory Model Interview Catalogue (EMIC). Contribution to cross-cultural research methods from a study of leprosy and mental health. Br J Psychiatry, 1992; 160: 819-830.

22 Krishna Kumari A, Harichandrakumar KT, Das LK, Krishnamoorthy K. Physical and psychosocial burden due to lymphatic filariasis as perceived by patients and medical experts. Trop Med Int Health, 2005; 10(6): 567-573.

23 Adhikari RK, Sherchand JB, Mishra SR, Ranabhat K, Pokharel A, Devkota P et al. Health-seeking behaviors and self-care practices of people with filarial lymphoedema in Nepal: a qualitative study. J Trop Med, 2015; 2015: 260359.

24 Person B, Addiss D, Bartholomew LK, Meijer C, Pou V, Gonzalvez G et al. "Can it be that god does not remember me": a qualitative study on the psychological distress, suffering, and coping of Dominican women with chronic filarial lymphedema and elephantiasis of the leg. Health Care Women Int, 2008; 29(4): 349-365.

25 Suma TK, Shenoy RK, Kumaraswami V. A qualitative study of the perceptions, practices and sociopsychological suffering related to chronic brugian filariasis in Kerala, Southern India. Ann Trop Med Parasitol, 2004; 97(8): 839-845.

26 Wijesinghe R, Wickremasinghe A, Ekanayake S, Perera M. Physical disability and psychosocial impact due to chronic filarial lymphoedema in Sri Lanka. Filaria J, 62007; 4.

27 Wijesinghe RS, Wickremasinghe AR. Physical, psychological, and social aspects of quality of life in filarial lymphedema patients in Colombo, Sri Lanka. Asia Pac J Public Health, 2012; 27(2): Np2690-701.

28 Kumari AK, Krishnamoorthy K, Harichandrakumar K, Das L. Health Related Quality of Life, an appropriate indicator to assess the impact of morbidity management and disability prevention activities towards elimination of lymphatic filariasis. Filaria J, 2007; 6: 8 .

29 Ton TG, Mackenzie C, Molyneux DH. The burden of mental health in lymphatic filariasis. Infect Dis Poverty, $2015 ; 4: 34$

30 Senturk VSR, Sagduyu A. Screening for mental disorders in leprosy patients: comparing the internal consistency and screening properties of HADS and GHQ-12. Lepr Rev, 2007; 78: 231-242.

31 Prachyapruit WPS, Jarutamara C. Psychiatric morbidity in leprosy patients: psychometric evaluated by the General Health Questionnaire-28 (translated Thai version). Thai J Dermaol, 2011; 27(3): 151-162.

32 George A, Khora T, Das P, Rao PS. Nursing interventions to manage anxiety levels of female inpatients admitted first time in a leprosy hospital. Indian J Lepr, 2013; 85(1): 19-25.

33 Nishida M, Nakamura Y, Aosaki N. Prevalence and characteristics of depression in a Japanese leprosarium from the viewpoints of social stigmas and ageing. A preliminary report. Lepr Rev, 2006; 77(3): 203-209.

34 Behere PB. Psychological reactions to leprosy. Lepr India, 1981; 53(2): 266-272.

35 Rocha-Leite C B-OR, Araújo-de-Freitas L, Machado P, Quarantini L. Mental disorders in leprosy: An underdiagnosed and untreated population. J Psychosom Res, 2014; 76: 422-425.

36 Vlassoff C, Khot S, Rao S. Double jeopardy: women and leprosy in India. World Health Stat Q, 1996; 49(2): 120-126.

37 Richard SA, Mathieu E, Addiss DG, Sodahlon YK. A survey of treatment practices and burden of lymphoedema in Togo. Trans R Soc Trop Med Hyg, 2006; 101(4): 391-397.

38 Wang LG, Hu YQ, Tang AQ, Fang HY, Gan WQ. Investigation on life quality of patients with chronic lymphatic filariasis in Yuhang district of Hangzhou]. Zhongguo Ji Sheng Chong Xue Yu Ji Sheng Chong Bing Za Zhi, 2011; 29(2): 159-161.

39 Kumaraswami TKS, Shenoy RK, V. A qualitative study of the perceptions, practices and socio-psychological suffering related to chronic brugian filariasis in Kerala, southern India. 2013; https://doi.org/101179/00034980 3225002435 .

40 Bakare Abdulfatai YA, Habib Zaharadeen OA. Anxiety and depression: A study of people with leprosy in Sokoto, North Western Nigeria. J Psychiatry, 2015; S1; 35-42.

41 Martindale S, Mkwanda SZ, Smith E, Molyneux D, Stanton MC, Kelly-Hope LA. Quantifying the physical and socio-economic burden of filarial lymphoedema in Chikwawa District, Malawi. Trans R Soc Trop Med Hyg, 2014; 108(12): 759-767.

42 Wijesinghe RS, Wickremasinghe AR, Ekanayake S, Perera MS. Physical disability and psychosocial impact due to chronic filarial lymphoedema in Sri Lanka. Filaria J, 2007; 6: 4. 
43 Gyapong M, Gyapong J, Weiss M, Tanner M. The burden of hydrocele on men in Northern Ghana. Acta Trop, 2000; 77(3): 287-294.

44 Dienye P, Gbeneol PB, Akani A. The association between giant hydrocele and depression in a rural clinic in Nigeria. Am J Men's Health, 2011; 5: 438-443.

45 Attama CMUR, Onyeama GM, Igwe MN. Psychiatric morbidity among subjects with leprosy and albinism in South East Nigeria: A comparative study. Ann Med Health Sci Res, 2015; 5(3): 197-204.

46 Erinfolami AAJ. A case control study of psychiatric morbidities among subjects with leprosy in Lagos, Nigeria. Int J Psychiatry Med, 2009; 39(1): 89-99.

47 Nagargoje Anita MGR, Deshmukh SB, Saboo AV. Psychiatric co-morbidity in persons with hansen's disease. $J$ Evidence Based Medicine Healthcare, 2015; 2(19): 2872-2881.

48 Ajibade O, Femi AA. Prevalence, management and percieved psychological impacts of leprosy diesease in National Tuberculosis and Leprosy Training Centre, Saye Village, Zaria. Int J Social Sci Humanities Invention, 2015; 2: 1298-1297.

49 Washington Group on Disability Statistics. Extended Question Set on Functioning (WG ES-F). 2010.

50 Price VG. Factors preventing early case detection for women affected by leprosy: a review of the literature. Global Health Action, 2017; 2: 1360550.

51 Sayce L. Stigma, discrimination and social exclusion: What's in a word? J Ment Health, 1998; 7(4): 331-343.

52 Weiss MG, Ramakrishna J, Somma D. Health-related stigma: rethinking concepts and interventions. Psychol Health Med, 2006; 11(3): 277-287.

53 van Brakel WH. Measuring leprosy stigma-a preliminary review of the leprosy literature. Int J Lepr Other Mycobact Dis, 2003; 71(3): 190-197.

54 Mitjà O, Marks M, Bertran L, Kollie K, Argaw D, Fahal AH et al. Integrated control and management of neglected tropical skin diseases. PLoS Negl Trop Dis, 2017; 11(1): e0005136-e.

55 NLR. SkinApp The mobile health tool by NLR2019.

56 World Health Organisation. Skin NTDs App. 2019.

57 London School of Hygiene \& Tropical Medicine. News: $£ 5$ million project to tackle tropical diseases of the skin 2019 [Available from: https://www.lshtm.ac.uk/newsevents/news/2019/ps5-million-project-tackle-tropical-dis eases-skin.

58 Chisholm D, Sweeny K, Sheehan P, Rasmussen B, Smit F, Cuijpers P et al. Scaling-up treatment of depression and anxiety: a global return on investment analysis. Lancet Psychiatry, 2016; 3(5): 415-424. 